\title{
Correction: The Impact of COVID-19 Management Policies Tailored to Airborne SARS-CoV-2 Transmission: Policy Analysis
}

Charles Roberto Telles ${ }^{1^{*}}$, BSc; Archisman Roy $^{2^{*}}$, BSc; Mohammad Rehan Ajmal ${ }^{3 *}$, PhD; Syed Khalid Mustafa ${ }^{4^{*}}$, $\mathrm{PhD}$; Mohammad Ayaz Ahmad ${ }^{5^{*}}, \mathrm{PhD}$; Juan Moises de la Serna ${ }^{6^{*}}, \mathrm{PhD}$; Elisandro Pires Frigo ${ }^{7^{*}}, \mathrm{PhD}$; Manuel Hernández Rosales ${ }^{8 *}, \mathrm{PhD}$

${ }_{1}^{1}$ Internal Control Center, Secretary of State for Education and Sport of Paraná, Curitiba, Brazil

${ }^{2}$ Mathematics Group, Department of Physics, Faculty of Science, Institute of Science, Banaras Hindu University, Varanasi, India

${ }^{3}$ Department of Biochemistry, Faculty of Science, University of Tabuk, Tabuk, Saudi Arabia

${ }^{4}$ Department of Chemistry, Faculty of Science, University of Tabuk, Tabuk, Saudi Arabia

${ }^{5}$ Department of Physics, Faculty of Science, University of Tabuk, Tabuk, Saudi Arabia

${ }^{6}$ Universidad Internacional de la Rioja, Madrid, Spain

${ }^{7}$ Federal University of Paraná, Curitiba, Brazil

${ }^{8}$ Programa Universitario de Estudios Sobre la Ciudad, National Autonomous University of Mexico, Mexico City, Mexico

*all authors contributed equally

\section{Corresponding Author:}

Charles Roberto Telles, BSc

Internal Control Center

Secretary of State for Education and Sport of Paraná

Av Água Verde, 2140

Curitiba, 80240-900

Brazil

Phone: 5541996056321

Email: charlestelles@ @eed.pr.gov.br

\section{Related Article:}

Correction of: https://publichealth.jmir.org/2021/4/e20699/

(JMIR Public Health Surveill 2021;7(5):e30007) doi: 10.2196/30007

In "The Impact of COVID-19 Management Policies Tailored to Airborne SARS-CoV-2 Transmission: Policy Analysis" (JMIR Public Health Surveill 2021;7(4):e20699), the authors noted one error.

The academic degree of author Archisman Roy has been corrected from "MSc" to "BSc."
The correction will appear in the online version of the paper on the JMIR website on May 3, 2021, together with the publication of this correction notice. Because this was made after submission to PubMed, PubMed Central, and other full-text repositories, the corrected article has also been resubmitted to those repositories.

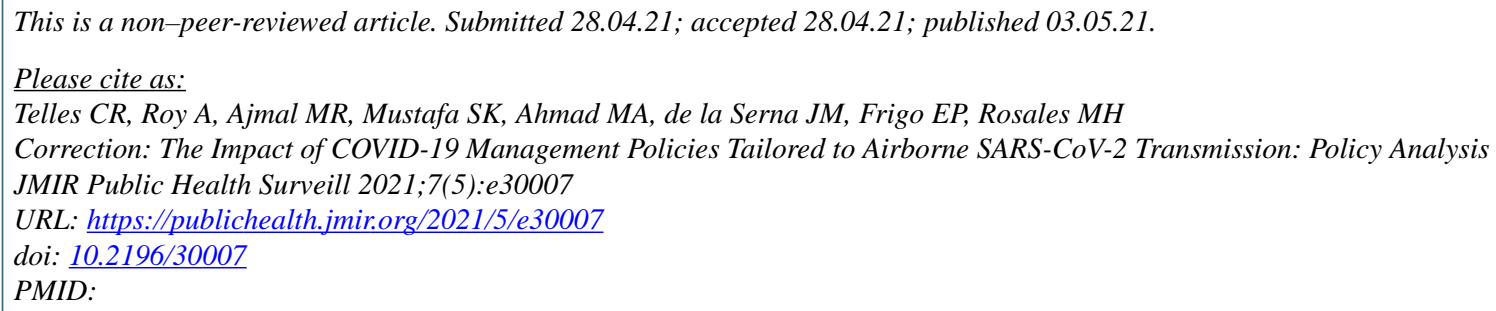

(C) Charles Roberto Telles, Archisman Roy, Mohammad Rehan Ajmal, Syed Khalid Mustafa, Mohammad Ayaz Ahmad, Juan Moises de la Serna, Elisandro Pires Frigo, Manuel Hernández Rosales. Originally published in JMIR Public Health and Surveillance (https://publichealth.jmir.org), 03.05.2021. This is an open-access article distributed under the terms of the Creative Commons 
Attribution License (https://creativecommons.org/licenses/by/4.0/), which permits unrestricted use, distribution, and reproduction in any medium, provided the original work, first published in JMIR Public Health and Surveillance, is properly cited. The complete bibliographic information, a link to the original publication on https://publichealth.jmir.org, as well as this copyright and license information must be included. 